\title{
Forces modeling in a surface peripheral grinding process with the use of various design of experiment (DoE)
}

\author{
Modelowanie sił w szlifowaniu obwodowym płaszczyzn \\ według różnych planów badawczych
}

\section{WITOLD HABRAT \\ MARCIN ŻÓŁKOŚ \\ JANUSZ ŚWIDER \\ ELŻBIETA SOCHA *}

The paper presents forces modeling with the use of DoE models, such as (Box-Wilson) central composite design in face centered variant (CCF) and Box-Behnken design in a surface peripheral grinding process of $100 \mathrm{Cr} 6$ steel with M3X60K5VE01-35 grinding wheel. Experiment design and result analysis were done with the use of Design-Expert software. Force models, obtained with application of selected designs of experiment, were compared on the basis of the coefficient of determination, and values of residual standard deviation.

KEYWORDS: peripheral grinding, design of experiment, $100 \mathrm{Cr} 6$, central composite design, Box-Behnken design

Design of experiment (DoE) is widely used to characterize processes and create empirical models. It reduces the number of measurements necessary to carry out.That translates into shortening the time spent on measurements and reducing material consumption, which in a consequence, reduces research costs. The selection of experimental design suitable for a given process is very important due to the accuracy and correctness of the obtained results, i.e. the mathematical model relationships describing selected process variables [1-3].

One of the methods used in designing of experiments is the surface response method (RSM) - multicomponent research designs (including Box-Behnken and central composite face centered design - CCF) are based on it. It is useful in modeling and analysis of phenomena (processes) in which several variables affect the output value. Models obtained by this method can be the basis for optimizing process inputs due to the adopted objective function [2-4].

Modeling of forces in the grinding process and thus making it possible to determine their values before machining is

\footnotetext{
* dr inż. Witold Habrat (witekhab@prz.edu.pl), mgr inż. Marcin Żółkoś (markos@prz.edu.pl) - Politechnika Rzeszowska, Wydział Budowy Maszyn i Lotnictwa; dr inż. Janusz Świder (swider@cerel.pl) - Instytut Energetyki Oddział Ceramiki CEREL; dr inż. Elżbieta Socha (elzbieta.socha@andre.com.pl)-Andre Abrasive Articles
}

important because of their relationship to the deformation of the workpiece and to the technological surface layer [5].

The paper analyzes the impact of the applied experimental design on the form and parameters of models describing the influence of selected parameters of the $100 \mathrm{Cr} 6$ steel peripheral grinding process on the value of grinding force components. The form and parameters of the models were determined based on the results of the experiment conducted using the central composite face centered design (CCF) and the Box-Behnken design.

\section{Experimental study conditions}

The tests of the surface peripheral grinding process were carried out on a test stand equipped with a $\mathrm{G}+\mathrm{H}$ FS $640 \mathrm{Z}$ surface grinder, Kistler 9121 piezoelectric dynamometer and a Kistler Type 5019 A amplifier. The stand was also equipped with a high pressure cooling system with a needle nozzle through which the coolant was fed with a flow rate of $22 \mathrm{l} / \mathrm{min}$ over the entire width of the grinding wheel $[6,7]$.

The machined material was $100 \mathrm{Cr} 6$ steel, through hardened and tempered to $58 \mathrm{HRC}$ hardness. A peripheral grinding wheel from Andre Abrasive Articles with the designation 7-300x50x76.2 P100; F10; G10 M3X60K5VE01-35 was used for the tests. The grinding wheel had abrasive grains with an average size of $275 \mu \mathrm{m}$ from monocrystalline corundum, with a $30 \%$ share of microcrystalline electro-corundum, bonded with vitrified binder [8]. The tests were carried out in a surface peripheral up grinding setup, where machined surface was $30 \mathrm{~mm}$ wide and $50 \mathrm{~mm}$ long. Before each measurement pass, the dressing of the grinding wheel with single grain diamond dresser was performed with constant parameters:

- peripheral speed $v_{d}=25 \mathrm{~m} / \mathrm{s}$,

- dressing depth $a_{\text {ed }}=0.02 \mathrm{~mm}$,

- number of passes $i_{d}=3$,

- coverage rate $k_{d}=6 \div 7$.

Next pass was made with grinding depth $0.002 \mathrm{~mm}$ and feed rate $1000 \mathrm{~mm} / \mathrm{min}$ to remove loose grains remaining after the sharpening process of the grinding wheel, and one sparking pass. Afterwards a machining pass took place, for which values of the normal and tangential component of the 
grinding force were recorded. After the measurement pass, three sparking passes were made to provide a constant machining allowance for the next pass.

The input factors influencing the components of grinding force in the process under investigation were the following technological parameters:

- grinding speed $v_{\mathrm{s}}=25 \div 35 \mathrm{~m} / \mathrm{s}$,

- feed rate $v_{f}=1000 \div 7000 \mathrm{~mm} / \mathrm{min}$,

- grinding depth $a_{e}=0.01 \div 0.03 \mathrm{~mm}$.

The values of the input parameters in the given ranges assumed three variation levels. In order to determine the impact of the experimental design on the model of the grinding force components, the experiment was designed using two designs based on the response surface method (RSM) - the central composite face centered design (CCF) and the Box-Behnken design. The central composite circumscribed design (CCC) was rejected due to the generation of star points outside the defined area of input parameters. For the given variation ranges of the input parameters, the negative values of feed rate $v_{f}$ and the grinding depth $a_{e}$ were obtained, which is impossible to obtain.

The experiment was carried out according to appropriate (for selected experimental designs) sets of process input parameters values generated using the Design-Expert software (see table).

TABLE. List of input parameters and measured values of grinding force components for considered experimental designs

\begin{tabular}{|c|c|c|c|c|c|}
\hline \multicolumn{6}{|c|}{ Box-Behnken Design } \\
\hline No & $v_{s}, \mathrm{~m} / \mathrm{s}$ & $V_{t}, \mathrm{~mm} / \mathrm{min}$ & $a_{e}, \mathrm{~mm}$ & $F_{n}, \mathrm{~N}$ & $F_{t}, \mathrm{~N}$ \\
\hline 1. & 25 & 1000 & 0.02 & 109.0 & 37.7 \\
\hline 2. & 35 & 1000 & 0.02 & 89.1 & 32.7 \\
\hline 3. & 25 & 7000 & 0.02 & 218.1 & 88.2 \\
\hline 4. & 35 & 7000 & 0.02 & 191.1 & 75.8 \\
\hline 5. & 25 & 4000 & 0.01 & 107.9 & 35.3 \\
\hline 6. & 35 & 4000 & 0.01 & 84.6 & 30.6 \\
\hline 7. & 25 & 4000 & 0.03 & 281.7 & 124.4 \\
\hline 8. & 35 & 4000 & 0.03 & 249.4 & 102.4 \\
\hline 9. & 30 & 1000 & 0.01 & 59.5 & 18.5 \\
\hline 10. & 30 & 7000 & 0.01 & 103.2 & 38.2 \\
\hline 11. & 30 & 1000 & 0.03 & 137.1 & 53.1 \\
\hline 12. & 30 & 7000 & 0.03 & 293.6 & 120.9 \\
\hline 13. & 30 & 4000 & 0.02 & 178.6 & 73.6 \\
\hline 14. & 30 & 4000 & 0.02 & 179.8 & 72.8 \\
\hline 15. & 30 & 4000 & 0.02 & 188.3 & 77.1 \\
\hline 16. & 30 & 4000 & 0.02 & 193.4 & 77.9 \\
\hline 17. & 30 & 4000 & 0.02 & 187.3 & 76.8 \\
\hline \multicolumn{6}{|c|}{ Central Composite Face Centered Design CCF } \\
\hline No & $v_{s}, \mathrm{~m} / \mathrm{s}$ & $V_{t}, \mathrm{~mm} / \mathrm{min}$ & $a_{e}, \mathrm{~mm}$ & $F_{n}, \mathrm{~N}$ & $F_{t}, \mathrm{~N}$ \\
\hline 1. & 25 & 1000 & 0.01 & 74.6 & 18.7 \\
\hline 2. & 35 & 1000 & 0.01 & 63.3 & 19.5 \\
\hline 3. & 25 & 7000 & 0.01 & 133.4 & 43.5 \\
\hline 4. & 35 & 7000 & 0.01 & 111.5 & 38.7 \\
\hline 5. & 25 & 1000 & 0.03 & 205.7 & 77.9 \\
\hline 6. & 35 & 1000 & 0.03 & 157.6 & 58.4 \\
\hline 7. & 25 & 7000 & 0.03 & 339.3 & 133.9 \\
\hline 8. & 35 & 7000 & 0.03 & 311.5 & 114.7 \\
\hline 9. & 25 & 4000 & 0.02 & 226.5 & 86.7 \\
\hline 10. & 35 & 4000 & 0.02 & 189.0 & 71.9 \\
\hline 11. & 30 & 1000 & 0.02 & 109.2 & 37.5 \\
\hline 12. & 30 & 7000 & 0.02 & 210.4 & 80.4 \\
\hline 13. & 30 & 4000 & 0.01 & 106.2 & 36.0 \\
\hline 14. & 30 & 4000 & 0.03 & 295.2 & 113.0 \\
\hline 15. & 30 & 4000 & 0.02 & 202.2 & 75.6 \\
\hline 16. & 30 & 4000 & 0.02 & 204.6 & 76.9 \\
\hline 17. & 30 & 4000 & 0.02 & 212.7 & 79.1 \\
\hline 18. & 30 & 4000 & 0.02 & 211.6 & 78.9 \\
\hline 19. & 30 & 4000 & 0.02 & 214.7 & 80.7 \\
\hline 20. & 30 & 4000 & 0.02 & 219.4 & 82.2 \\
\hline
\end{tabular}

\section{Results of experimental research}

After performing the tests, the obtained values of grinding force components (table) were analyzed in the DesignExpert software. A modified (containing only statistically significant elements) square model was selected for fitting. The significance of the influence of individual input parameters and their interactions was determined based on the ANOVA analysis of variance. Next, the quality of fitting the obtained models to the values measured for a given experimental design was determined based on the determination coefficients $R^{2}$ and the standard deviation of the residual component $\mathrm{s}$. The $\mathrm{s}$ values were determined for theoretical values calculated from model relationships describing the components of grinding force and experimental values measured for particular experimental designs.

Fig. 1 and fig. 2 show the points of the research plan, in which the obtained values are above (red dots) or below (gray dots) predicted (theoretical) values.
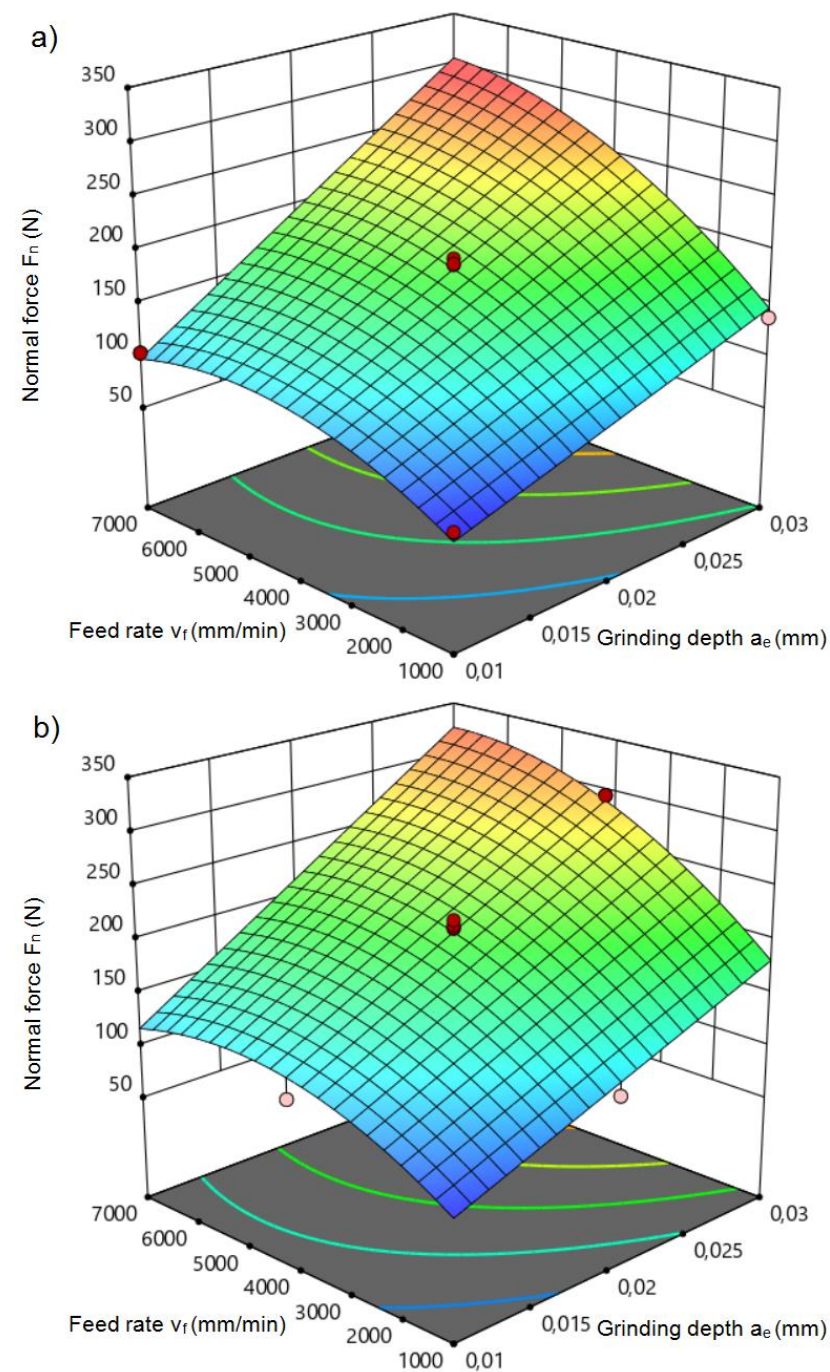

Fig. 1. Dependence of grinding force normal component $F_{\mathrm{n}}$ from feed rate $v_{f}$ and grinding depth $a_{e}$ for grinding speed $v_{s}=30 \mathrm{~m} / \mathrm{s}$, obtained for the: a) Box-Behnken design, b) CCF design

Based on the analysis of the results, model (1) and (2) dependences were obtained describing the normal $F_{\mathrm{n}}$ component as a function of the process input parameters. The dependence (1) was obtained for the tests carried out according to the Box-Behnken design, and the dependence (2) for the tests carried out according to the CCF design (in both cases the models take into account only statically significant input parameters): 
$F_{n}=56,018-2,562 \cdot v_{s}+2,798 \cdot 10^{-2} \cdot v_{f}+3822,5 \cdot a_{e}+$

$0,94 \cdot v_{f} \cdot a_{e}-3,706 \cdot 10^{-6} \cdot v_{f}^{2}$

$F_{n}=61,188-2,932 \cdot v_{s}+3,398 \cdot 10^{-2} \cdot v_{f}+5194,6 \cdot a_{e}+$

$0,752 \cdot v_{f} \cdot a_{e}-4,062 \cdot 10^{-6} \cdot v_{f}^{2}$

From the given dependencies and the responce surface, the effect of the grinding speed $v_{\mathrm{s}}$ on the value of the normal force $F_{\mathrm{n}}$ is small compared to the other input parameters. For the model (1) the coefficient of determination was $R^{2}=$ 0.988 , and the standard deviation of the residual component $s=9.07$. However, for the model (2), these values were respectively: $R^{2}=0.986$ and $s=10.37$. This indicates a slightly better fit of the model for normal force $F_{\mathrm{n}}$ in the case of the Box-Behnken design.

Fig. 2 presents the surfaces described by equations (3) and (4), presenting dependencies of the tangential component $F_{\mathrm{t}}$ of the grinding force from the grinding depth $a_{e}$ and the feed rate $v_{f}$ for grinding speed $v_{s} 30 \mathrm{~m} / \mathrm{s}$.
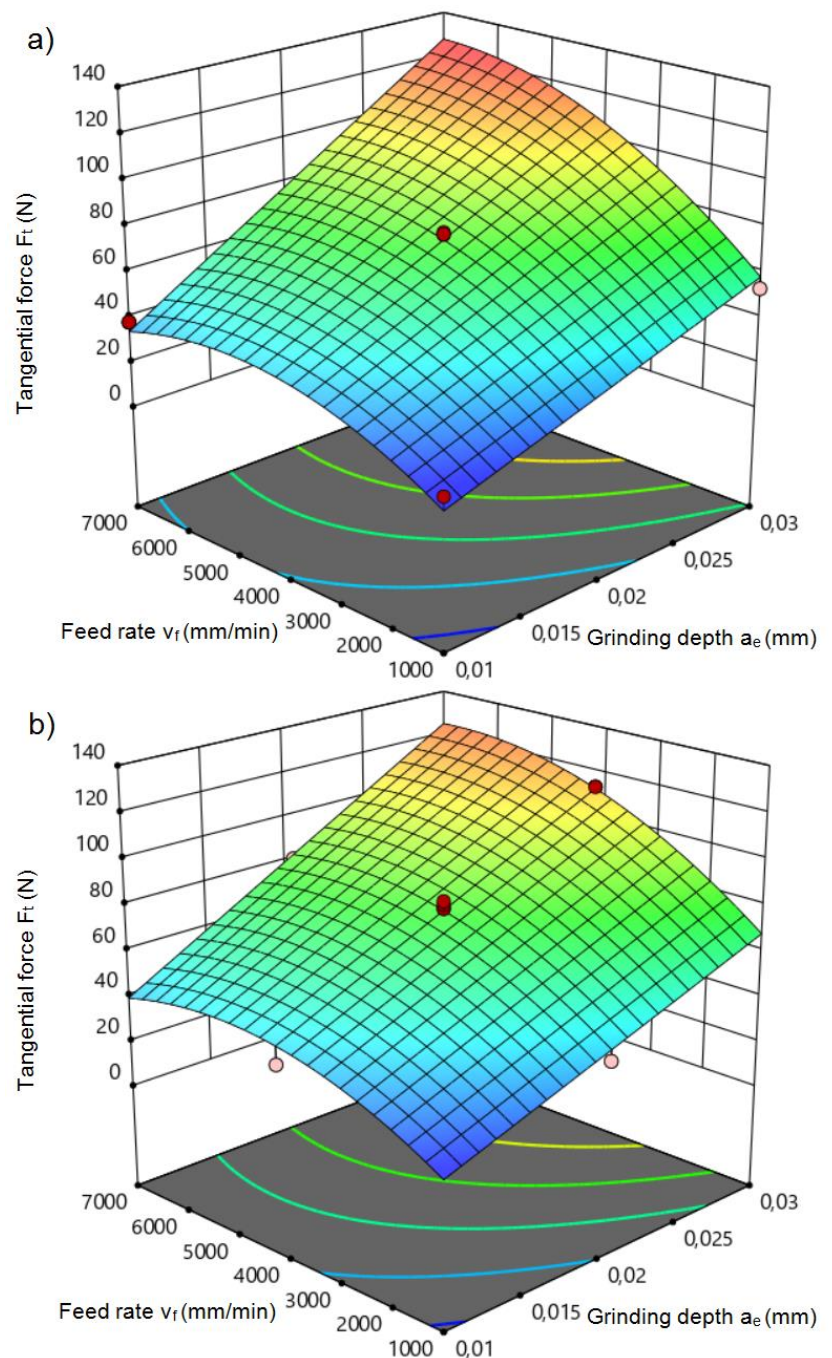

Fig. 2. Dependence of grinding force tangential component $F_{\mathrm{t}}$ from feed rate $v_{t}$ and grinding depth $a_{e}$ for grinding speed $v_{s}=30 \mathrm{~m} / \mathrm{s}$, obtained for the: a) Box-Behnken design, b) CCF design

For the tangential component $F_{\mathrm{t}}$ of the grinding force, identical analysis of the results was performed and model dependences were obtained, describing this component as a function of the process input parameters, obtained for the Box-Behnken design (3) and for the central composite face centered design CCF (4):
$F_{t}=10,785-1,102 \cdot v_{s}+1,411 \cdot 10^{-2} \cdot v_{f}+1874,16 \cdot a_{e}+$

$0,401 \cdot v_{f} \cdot a_{e}-1,823 \cdot 10^{-6} \cdot v_{f}^{2}$

$F_{t}=-39,597+0,585 \cdot v_{s}+1,497 \cdot 10^{-2} \cdot v_{f}+4879,16 \cdot a_{e}-$

$86,75 \cdot v_{s} \cdot a_{e}+0,285 \cdot v_{f} \cdot a_{e}-1,753 \cdot 10^{-6} \cdot v_{f}^{2}$

The analysis of variance carried out for the dependence (3) showed the influence significance on the tangential force $F_{\mathrm{t}}$ of the same input parameters as in the case of dependence (1) and (2). In turn for the dependence (4) the analysis showed the influence of the same parameters as for the dependence (3) and additionally - the interaction of grinding speed $v_{s}$ and the grinding depth $a_{e}$.

The very small influence of the grinding speed $v_{s}$ on tangential forces $F_{\mathrm{t}}$ valueswas also noticed, as compared to the influence of the feed rate $v_{f}$ and the grinding depth $a_{e}$. For the model dependence (3), the coefficient of determination was $R^{2}=0.966$, and the standard deviation of the residual component $s=5.86$. For the model dependence (4), these values were respectively: $R^{2}=0.987$ and $s=$ 3.49. This indicates a better fit of the tangential force model $F_{\mathrm{t}}$ when using the CCF design.

\section{Conclusions}

On the basis of the obtained results, it is possible to formulate the following conclusions:

- in the case of both experimental designs, similar relations were obtained describing the normal component $F_{\mathrm{n}}$, differing only slightly in the values of coefficients;

- on the basis of the determination coefficients $R^{2}$ and the standard deviation of the residual component $s$, it can be concluded that for normal component $F_{\mathrm{n}}$ a slightly better fit was obtained for the Box-Behnken design,

- in case of applying the CCF design, the form of the dependence describing the tangential component $F_{\mathrm{t}}$ was obtained, which differed from the one obtained for the BoxBehnken design by an additional factor of the equation, which is the interaction of the grinding speed $v_{\mathrm{s}}$ and the grinding depth $a_{\mathrm{e}}$;

- on the basis of the determination coefficients $R^{2}$ and the standard deviation of the residual component $s$, it can be concluded that for the tangential component $F_{\mathrm{t}}$, a slightly better fit was obtained when the experiment was designed according to the central composite face centered design (CCF);

- both methods of designing the experiment give comparable results, with each method achieving an increased model fit for different component of the grinding force;

- the lower number of measurements necessary to be performed and the increased model fit accuracy for the more important in this process normal grinding force component $F_{\mathrm{n}}$ works in favor of the Box-Behnken design.

\section{REFERENCES}

1. Krajnik P., Kopač J. "Adequacy of matrix experiment in grinding". Journal of Materials Processing Technology. 157-158 (2004): pp. 566-572.

2. Rudrapati R., Pal P.K., Bandyopadhyay A. "Modeling and optimization of machining parameters in cylindrical grinding process". The International Journal of Advanced Manufacturing Technology. 82, 9-12 (2016): pp. 2167-2182.

3. Montgomery D.C. "Design and Analysis of Experiments". Hoboken, NJ: John Wiley \& Sons, 2017.

4. Markopoulos A.P., Habrat W., Galanis N.I., Karkalos N.E. "Modelling and Optimization of Machining with the Use of Statistical Methods and Soft Computing". Design of Experiments in 
Production Engineering. Switzerland: Springer International Publishing, 2016.

5. Habrat W., Krupa K., Laskowski P. „Modelowanie sił w procesie szlifowania stopu Inconel 718 ściernicami z mikrokrystalicznego korundu spiekanego". Mechanik. 86, 8-9 (2013): pp. 174-180.

6. Babiarz R., Żyłka Ł., Płodzień M. „Koncepcja budowy układu wysokociśnieniowego chłodzenia procesu szlifowania stopów lotniczych". Mechanik. 87, 8-9 CD (2014): pp. 4-7.

7. Kieraś S., Nadolny K., Wójcik R. „Aktualny stan wiedzy i techniki w zakresie chłodzenia i smarowania strefy obróbki w procesach szlifowania". Mechanik. 88, nr 8-9 CD1 (2015): pp. 204211.

8. www.andre.com.pl/ (accessed: 20.05.2018 r.).

Translation of scientific articles, their computer composition and publishing them on the website www.mechanik.media.pl by original articles in Polish is a task financed from the funds of the Ministry of Science and Higher Education designated for dissemination of science. 